\title{
Frederico, meu pai
}

\author{
Frederico, my father
}

Frederico, mi padre

Constança Simões Barbosa ${ }^{1}$

${ }_{1}$ Centro de Pesquisas Aggeu Magalhães, Fundação Oswaldo Cruz, Recife, Brasil.

Correspondência C. S. Barbosa

Centro de Pesquisas Aggeu Magalhães, Fundação Oswaldo Cruz, Recife, Brasil. Av. Prof. Moraes Rego s/n, Recife, PE 50670-420, Brasil. constanca.barbosa@gmail.com
Eu fui a sua primeira filha e ele foi pai e mãe nos meus primeiros meses de vida... ligação afetiva profunda que perdurou durante toda a nossa longa convivência.

Meu pai casou aos 33 anos com Lilia Gayoso, minha mãe, dez anos mais jovem que ele, linda e cheia de alegria. Após o primeiro parto, minha mãe teve uma séria depressão, permanecendo em tratamento hospitalar por meses, durante os quais meu pai se dedicou a mim com extremo zelo e carinho. Para poder conciliar os cuidados com a filha recém-nascida e seu trabalho, ele mudou-se para a casa da minha madrinha Elza Campozana, irmã dileta que morava na Av. Rosa e Silva (Recife, Pernambuco), próximo ao Instituto Aggeu Magalhães, onde meu pai era Diretor na época. Desse modo, ele acompanhava e participava dos cuidados com sua filha, almoçava em casa e à noite me acalentava até adormecermos juntos. E assim, durante toda a sua vida foi um pai maravilhoso e cúmplice, apesar das inúmeras ausências devido às viagens de trabalho.

Nossas primeiras moradias, no bairro de Boa Viagem, foram em casas alugadas e, em 1955, meu pai comprou um bom terreno neste bairro, rascunhou e definiu a planta do que seria o nosso lar durante os 15 anos vindouros. A casa era grande e um andar inteiro foi destinado à biblioteca pessoal dele, da qual fazia parte o enorme acervo herdado do pai e do avô, conhecidos médicos e intelectuais recifenses. Esse era o seu local predileto quando estava em casa e onde eu podia ter acesso... desde que fosse para ler em silêncio. Assim, ele incentivou meu gosto pela literatura, recomendando clássicos nacionais e estrangeiros e estabelecendo uma prática deliciosa: após o jantar havia a leitura conjunta dos best sellers da época, que eu escutava fascinada, sentada no seu colo enquanto ele degustava a sua dose diária de uísque.

Aos 6 anos fiz minha estreia, como sua orgulhosa colaboradora, nas coletas de campo para captura de Culicídeos, na imensa extensão de manguezais que margeavam nossa casa em Boa Viagem. Montávamos as armadilhas luminosas que eu ia recolher sozinha no dia seguinte, muito zelosa do protocolo por ele determinado para o acondicionamento dos mosquitos capturados. Durante toda minha infância acompanhei meu pai em inúmeras viagens pelo interior de Pernambuco, nos seus estudos sobre a ecologia dos moluscos hospedeiros do Schistosoma mansoni, coletando e identificando exemplares de Biomphalaria. Nessas viagens, além dos ensinamentos profissionais, ele me mostrava o valor das coisas simples, a comer de tudo sem queixas e a não fazer cara feia em casas modestas e sem conforto. Ele apontava as injustas diferenças sociais, moldando minha consciência política sobre a origem e a cruel manutenção de tantas crianças famintas e doentes.

Na primeira infância, sofri de asma alérgica e foram muitas as noites com meu pai em vigília tentando aliviar meu sofrimento. Com o seu agu- 


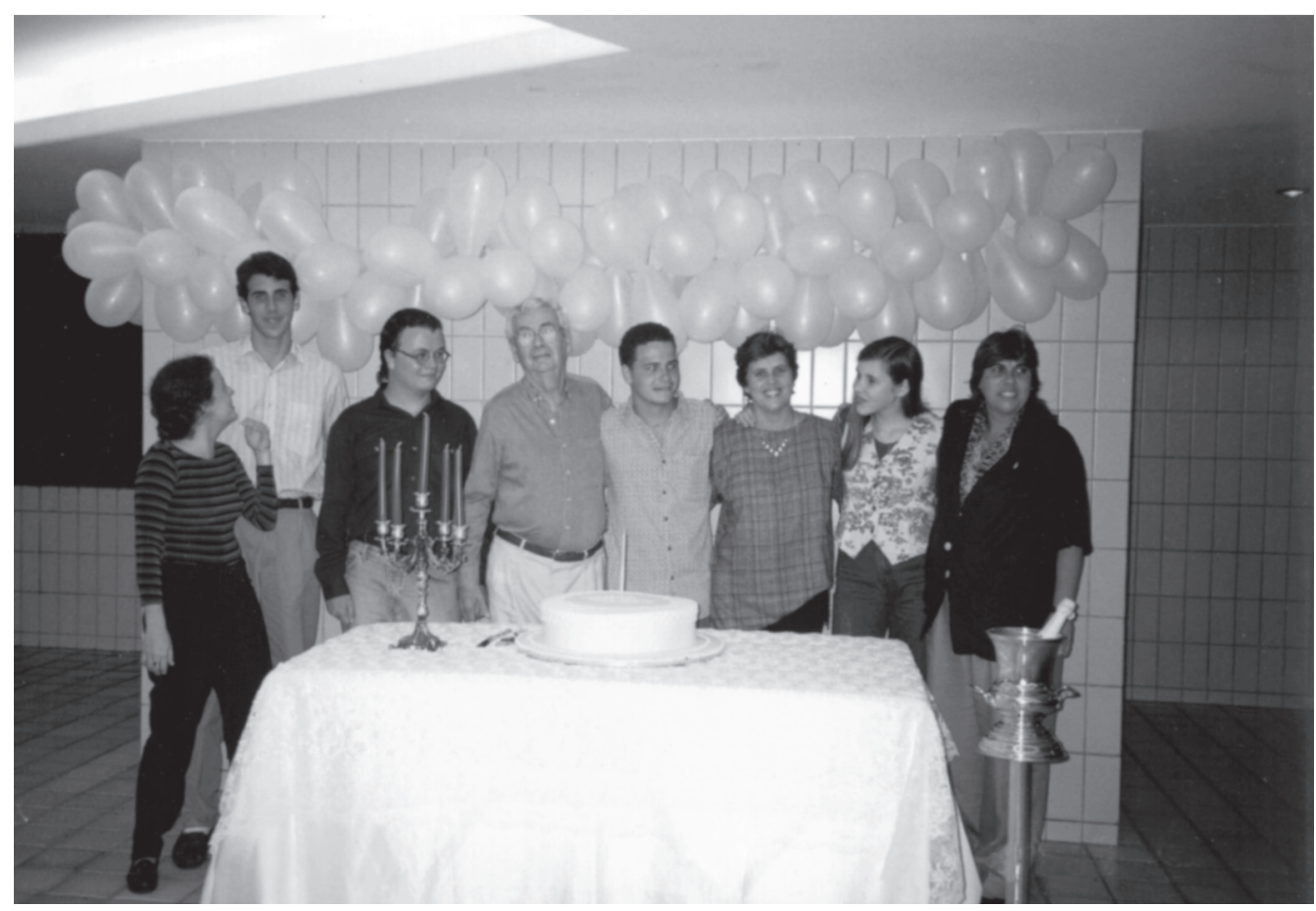

çado raciocínio epidemiológico, pareava minhas crises com vários indicadores ambientais até descobrir que os eventos asmáticos eram detonados sempre que o vento soprava da terra para o mar, levando os efluentes aéreos de uma fábrica de óleo de mamona até a nossa casa.

Em 1954, nasceu a sua segunda filha, Maria Fernanda. Minha mãe adoeceu novamente e minha avó materna veio morar conosco, assumindo para si os cuidados com minha irmã e paparicando meu pai com quitutes divinos que ele adorava, como as fritadas de aratu e ensopados de camarão pitu, pescados nos manguezais que não mais existem.

Próximo aos meus 10 anos de idade, percebendo a minha relação conflituosa com minha mãe, ele me seduz com a proposta de sair de casa para fazer o curso ginasial em São Paulo como aluna interna do colégio Sacre Coeur de Marie. Foi mais uma sábia e sensata influência dele na condução do crescimento pessoal dos filhos, tendo essa sua decisão me proporcionado uma excelente educação escolar de base, ao mesmo tempo incentivando uma postura autônoma e independente. Durante os anos em que estive fora de casa papai me enviava cartões postais dos lugares para onde viajava a trabalho, muitas cartas carinhosas e caixas de chocolates Kopenhagen. No final do ano ia me pegar para as férias escolares, algumas vezes aproveitando para retirar, em São Paulo, a viatura Rural Willys encomendada para os trabalhos de campo do Aggeu Magalhães. Economizava assim a taxa para a entrega desses carros em Recife e curtíamos viagens de memoráveis aprendizados pelas estradas de Minas Gerais e da Bahia.

Na década de 1960, Frederico idealizou e coordenou um projeto de vanguarda para o controle da esquistossomose em Pontezinha, Pernambuco, com visão e condutas holísticas sobre os determinantes socioculturais da endemia, valorizando a participação popular nas ações de controle e priorizando o saneamento. Como estudante do curso de Sociologia, participei desse projeto, engajada na equipe de Educação Sanitária liderada pela atuante educadora do Ministério da Saúde, Hortênsia de Hollanda. Muitos outros alunos tiveram valiosas experiências de trabalho e de conduta ética durante esse projeto. 
Escola Nacional de Saúde Pública/Fundação Oswaldo Cruz, Rio Janeiro, julho de 1996 (Acervo particular da autora). Iniciando pela esquerda: Luiz Jacintho da Silva, Maria Cecília Minayo, Frederico Simões Barbosa, Constança Simões Barbosa, Carlos Coimbra Jr., Maria do Carmo Leal, Adauto Araújo e Eduardo Freese.

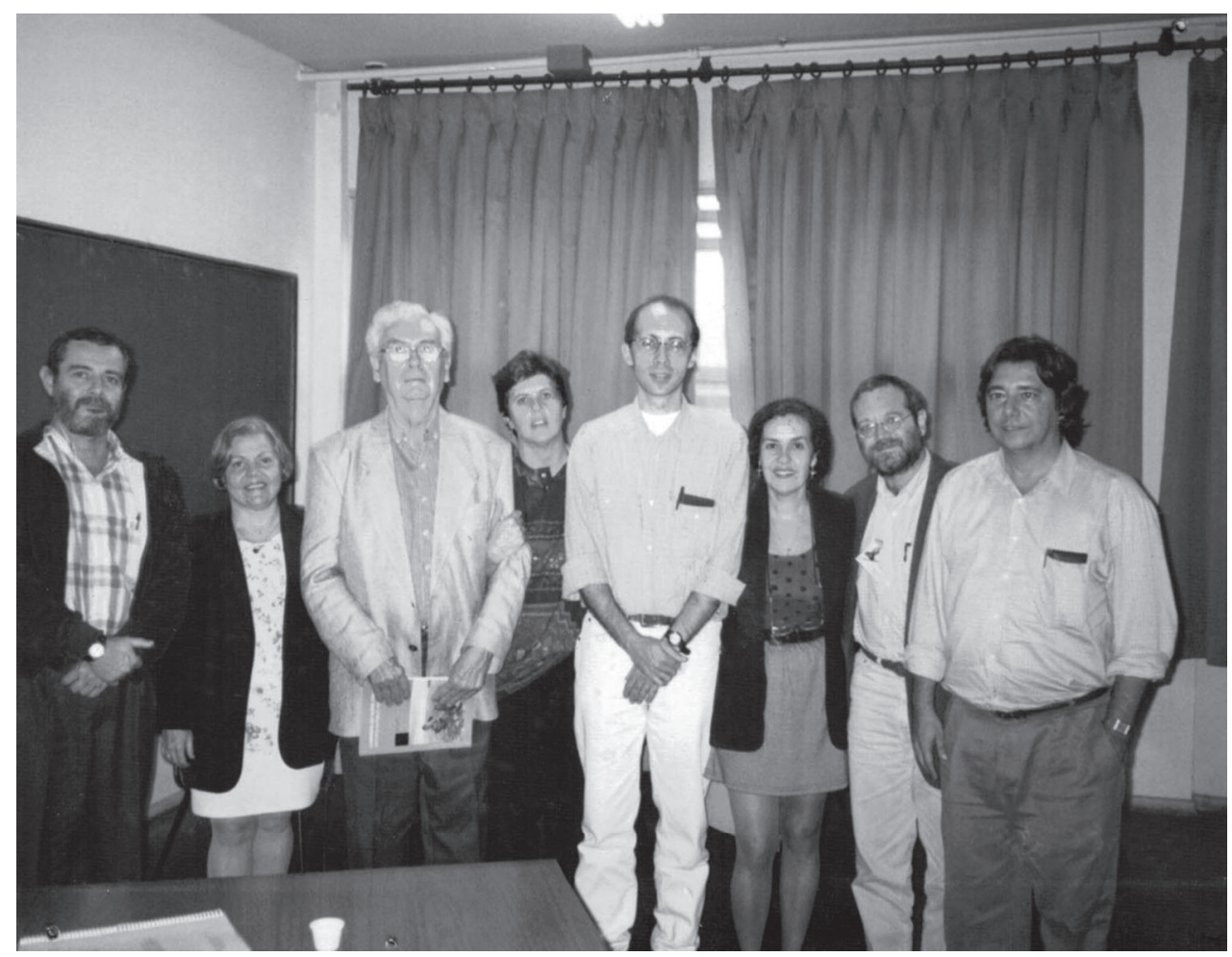

Em 1969, Frederico foi convidado pela Organização Mundial da Saúde (OMS) para coordenar o programa mundial de controle da esquistossomose, em Genebra na Suíça, lá permanecendo por dois anos. Antes de tomar a decisão, ele me chamou para uma conversa delicada e muito perturbadora. Fomos passeando até a beira mar onde ele me comunicou sobre o convite da OMS, me confidenciando também que estava enamorado por uma bióloga, Dalva Mello, que viajaria com ele e, no futuro, viria a ser sua segunda esposa. Pediu minha compreensão e também para cuidar da minha mãe e minha irmã enquanto estivesse ausente, me deixou uma procuração com plenos poderes e a posse dos seus salários para as despesas da casa. Com apenas 19 anos assumi esse pesado compromisso por amor e solidariedade, meu pai merecia uma segunda chance de ser feliz com uma nova companheira. Minha mãe, que já estava muito doente nessa época, faleceu em 1970.
Entre 1972 e 1981, Frederico passou a residir em Brasília, assumindo o Programa de Medicina Comunitária na Universidade de Brasília (UnB), e entre 1982 e 1983 foi para São Carlos como assessor pedagógico da área de saúde da Universidade Federal de São Carlos (UFSCar). Nesse período, eu estava casada e morava em Taubaté (São Paulo), onde fiz a faculdade de Biologia, vindo a trabalhar no Instituto Adolfo Lutz no setor de malacologia. Meu pai esteve presente no nascimento dos meus dois filhos, Leonardo e Lilia, e sempre trocávamos cartas e telefonemas sobre nossos trabalhos e nossas vidas. Em 1983, voltei ao Recife e a seu pedido assumi a coordenação da Estação Experimental de Campo do Centro de Pesquisas Aggeu Magalhães da Fundação Oswaldo Cruz (CPqAM/Fiocruz), criada por ele na década de 1970 para estudos de campo em área endêmica para esquistossomose. Em 1992, essa Estação passou à sede do CPqAM, passando a chamar Laboratório e Serviço de Referência em 
Foto 3

Pai e filha, momento feliz... Recife, 1994 (Acervo particular da autora).

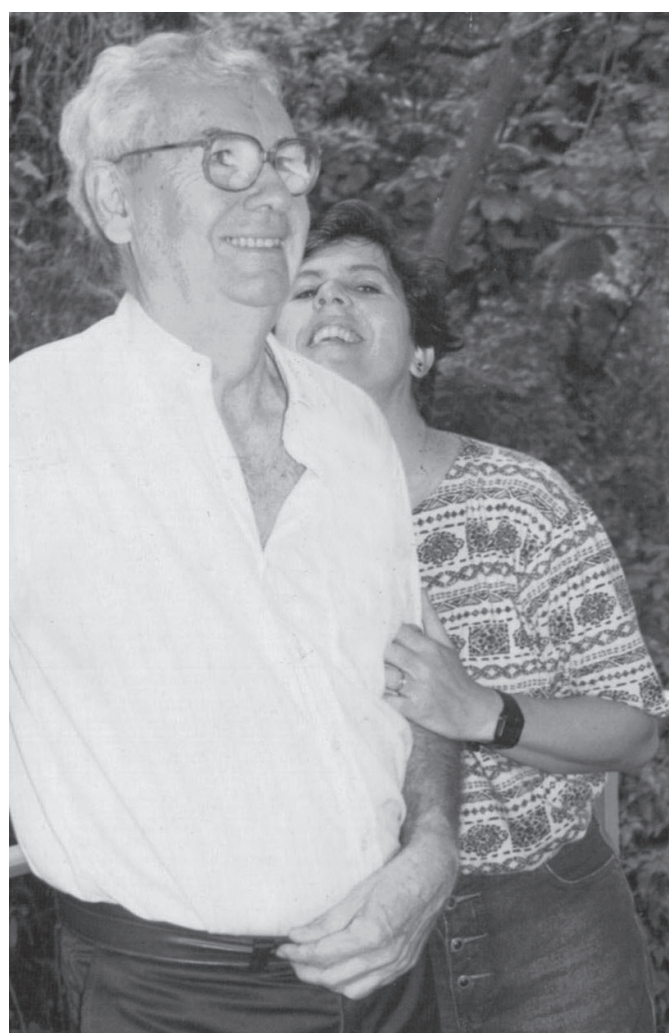

Esquistossomose. Em 1983, Frederico fez concurso para professor titular da Escola Nacional de Saúde Pública (ENSP) na Fiocruz, Rio de Janeiro, onde passou a residir após o final do seu casamento com Dalva, do qual teve três filhos: Fred (engenheiro de computação), Alessandra (professora de artes na Universidade Federal do Sul da Bahia) e Augusto (biologista molecular na Universidade de Auckland, Nova Zelândia). É deles o depoimento: "Meu pai, um ideal de vida, uma lição sobre o ser sensível, sobre a honestidade e o compromisso com o social. Saudade...”.

Entre 1985 e 1993, viveu no Rio de Janeiro como diretor e professor da ENSP, onde convivemos muito estreitamente quando lá estive para fazer meu doutorado sob sua orientação e a do professor Carlos Coimbra Jr.

Em 1997, recebeu o diagnóstico da doença de Parkinson e a meu pedido veio residir em Recife, morando ao nosso lado, porém em seu próprio apartamento. Permaneceu atuante ainda por vá- rios anos, e a convite da Dra. Eridan Coutinho frequentava o CPqAM diariamente como Assessor Científico da Diretoria. Essa foi a época de nossa maior e intensa proximidade e de profunda afetividade, eu o pegava de manhã para irmos ao trabalho onde almoçávamos juntos e depois ele retornava para casa com o seu motorista. Nesse período, talvez uns quatro anos, ele valorizava muito esses almoços em que discutia ciência e política com André Furtado, Eridan Coutinho, Sinval Brandão Filho, Mercia Arruda, entre outros companheiros que sentavam conosco à mesa.

Os domingos eram dedicados à família, saíamos invariavelmente para almoçar em bons restaurantes que ele fazia questão de escolher pelo cardápio e pelo bom atendimento, dando preferência aos frutos do mar acompanhados de um bom vinho. Minha irmã Fernanda e meus filhos Leo e Lilia partilharam desses momentos dos quais temos gratas e saudosas lembranças. Nas férias chegavam os filhos do segundo casamento, Ale, Gu e Fred, e a alegria dele era plena nesses encontros com filhos e netos.

Frederico foi um homem muito à frente da sua época, preconizando e adotando conceitos morais e sociais avançados, foi um humanista com profundo conhecimento filosófico, sociológico e antropológico. Praticava o que escrevia e tinha a generosidade e humildade de passar esses conhecimentos para os seus alunos, nos impregnando com novas verdades: “... a epidemiologia vai além de um simples instrumento de análise ... penetra profundamente no âmago dos problemas mais relevantes da vida humana ... se situa, como as ciências sociais, como instrumento valioso de transformação social" 1 (p. 139).

Era um homem gentil, calmo, introvertido, reflexivo, de extremo bom senso e poucas palavras, porém suas opiniões eram sempre ouvidas com muito respeito em qualquer plateia onde atuasse. Era um militante das esquerdas, mas sem filiação partidária. Era ateu, mas não se negava a discutir o sentido da vida e as possibilidades da finitude. Foi um pai muito generoso, compreensivo, amigo e amoroso, que persistentemente e com muito amor moldou profissional e moralmente seus filhos, mas que fundamentalmente se preocupava em prepará-los para serem independentes e felizes.

Eu tive o duplo privilégio de conviver com ele como filha e como colega de trabalho, aprendi muito e fui contaminada para sempre pelas suas afirmações: “...a produção científica deve ser simultaneamente um bem cultural e um instrumento de trabalho socialmente comprometido" 2 (p. 348) 
Frederico (chapéu na mão) e Constança em trabalho de campo na Comunidade Natuba, Pernambuco, 1992 (Acervo particular da autora).

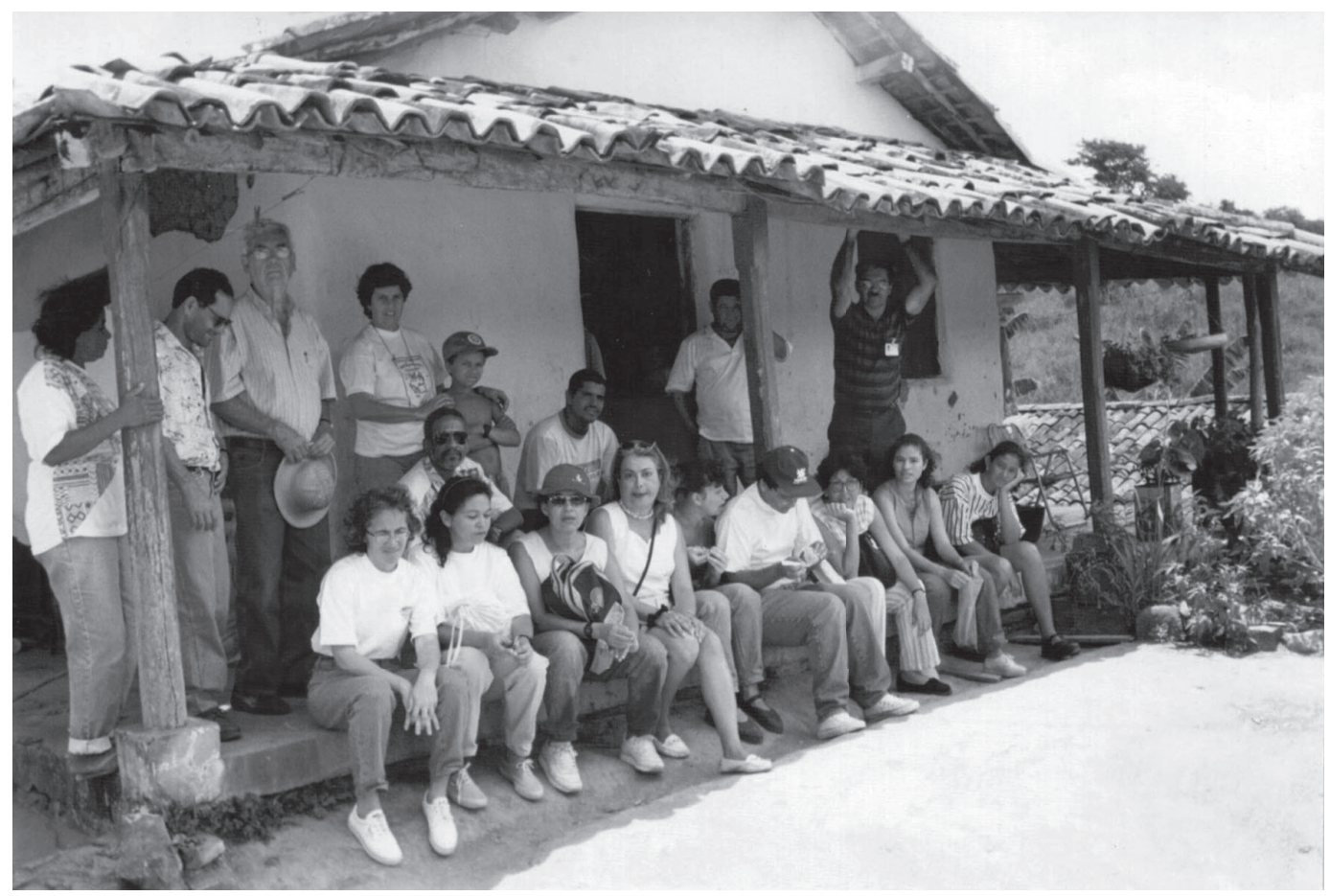

Tive a felicidade de estar ao seu lado e lhe proporcionar toda assistência, atenção e carinho nos difíceis últimos momentos da sua vida, quando a doença agravou, e estava segurando na sua mão quando ele exalou seu último suspiro às 5 horas da manhã do dia 8 de março de 2004.
1. Barbosa FS. A epidemiologia como instrumento de transformação. Cad Saúde Pública 1985; 1:137-9.

2. Barbosa FS. Política de investigação no Brasil. Cad Saúde Pública 1987; 3:343-51. 